\title{
Interests, Gender Differences, Impulsivity and Reflectivity among Year Three Pupils in London (U.K.) Schools
}

\author{
Walifa Rasheed-Karim ${ }^{1 *}$ \\ ${ }^{1}$ British Psychological Society, UK \\ * Corresponding Author: bebirasheed@yahoo.co.uk \\ Citation: Rasheed-Karim, W. (2020). Interests, Gender Differences, Impulsivity and Reflectivity among Year \\ Three Pupils in London (U.K.) Schools. International Journal of Childhood Education, 1(1), 1-13. \\ https://doi.org/10.33422/ijce.v1i1.9
}

\begin{abstract}
The achievement of year 3 pupils in the classroom may be influenced by how they are taught familiar topics. That is, it is suggested that pupils may develop interests such as hobbies which are related to academic studies at school. It is therefore hypothesised that the extent to which year 3 pupils are interested in school subjects is a major factor contributing to performances in terms of time taken to complete tasks, errors made during completion and the type of strategies pupils use for successful completion of tasks. The extent to which pupils make errors and the time it takes to complete matching tasks of interest, is used as an indicator of how 'reflective or impulsive' pupils are, and this has implications for academic achievement. Thirty girls and thirty boys, (7-8 years old) were recruited for a study across five primary schools in a London Borough (England, U.K.). Interest and lack of interest in things was elicited using an interview and simple matching tasks were used to establish performance on tasks of interest and disinterest. Boys generally made slightly more errors than girls and were quicker when making matches. Girls used ordered strategies to make matches compared with random/global strategies for boys. The implications for this research are: - training of pupils to problem-solve using appropriate strategies; establishing ways of developing students' subject interests and encouraging teachers to find ways of using suitable styles for individual students' needs who are either reflective or impulsive.

Key words: individual differences; cognitive styles; primary
\end{abstract}

\section{Introduction}

Many teachers are sometimes faced with the predicament of setting tasks which suit individuals' styles of learning and provide the appropriate learning environment which helps them to achieve learning goals. It may be that those who have a high success rate when it comes to problem solving are reflective and will take their time while problem solving. This would inevitably influence their achievement in the classroom. The aim of the research is to identify if interest in subject material influences children's performance in the classroom when they engage in problem-solving. It could be that being interested in a particular subject provides the facility for pupils to grasp significant concepts of a topic.

\section{Interests}

An examination of discussions of styles point to a definition by Snow (1992). He suggested that interests draw individuals' attention towards particular directions where the object of interest elicits excitement and joy or a challenge (Csikszentmihalyi, 1990). Additionally, Csikszentmihalyi and Nakamura (1989) identified intrinsic motivations as goal oriented and are chosen by individuals so that they are able to respond to their curiosity.

It is noteworthy that some children could be more interested in schoolwork or a particular area than others and this makes them learn more about it. Such interest may be symptomatic of the 
object's novelty (Loewenstein, 1994); internal motivating forces (Bandura, 1977); socialcultural constraints such as access individuals have to aspects of a culture, knowledge constraints and self-perceptions of ability (Deci, 1992). Kolb (1971) on the other hand, discussed that interest arises when characteristics of tasks and situations coincide with styles of individuals. Sternberg and Zhang (2001) concluded that dispositions of individuals and styles facilitate interests.

Research showed that academic interest is important in mathematical successes (Köller, Baumert \& Schnabel, 2001) and interest subsequently influences course choices among males and females. Others, such as Harackiewicz, Smith and Priniski (2018) and Abrantes, Lages and Seabra (2007) reported that settings which promote interest by tapping into prior interests of students result in motivated students who are better problem solvers. Furthermore, Abrantes et al. discussed that pedagogical strategies have relevance in increasing students' interest. Research does not address the need to implement 'interests' arising from hobbies and extracurricular activities into the curriculum of year 3 primary pupils. Also, the extent to which reflectivity and impulsivity are relevant to pupils' problem solving with respect to how interested they are in topics requires addressing.

Research in children with attention deficit hyperactive disorder (ADHD) shows that impulsivity reduces educational achievement (Spinella \& Miley, 2003). Others such as Cavilla (2017) reported that reflection enhanced metacognitive skills among students, resulting in improved performance and this is mainly evident at an affective level. That is, students exerted effort to achieve higher grades and changed ways of thinking of problem solving after lessons. This paper specifically addresses the argument that interest, and the impulsivity-reflectivity dimension plays an important part in problem-solving and this can be investigated by asking 7-8 year old girls and boys to complete simple matching tasks.

\section{Discussion of Impulsivity-Reflectivity}

\subsection{Evaluation}

Kagan, Moss and Sigel (1963) reasoned that reflection is the delay of decision-making in situations where a correct response is not obvious. The reflective person may complete less of a task but is careful not to make mistakes. The alternative is impulsivity, and this is a quick choice of an alternative without ample consideration of options. This rapid response most often results in incorrect choices, although most of the task is completed. Eska and Black (1971) however elucidated that those who complete many items accurately are 'quick' and individuals who finish few items with many errors are slow. Causes of reflection-impulsivity are unclear although cognitive stylists agree that any tendency to be either reflective or impulsive may be inherited. However, Kagan (1966) argued that people tend to have a relatively consistent style on tasks.

In terms of assessing pros and cons before making decisions, Messer (1976) concluded that the reflective individuals will spend more time evaluating hypotheses and tend to gather more information on which to base decisions. Such information is gathered more systematically than those who are impulsive. It was assumed by Kagan, Rosman, Day, Albert and Phillips (1964) and Kagan (1971) that if children pause and evaluate their answers, responding will be slower and more accurate. However, if children do not pause, their answers will be less accurate due to the fact they are less likely to evaluate answers.

\subsection{Global versus Detailed Analysis}

Researchers discussed how impulsive and reflective individuals process information in terms of global and detailed analysis. For example, Morgan (1997) reported that in school activities that require problem solving skills, impulsive children are less likely than their reflective peers 
to use effective strategies. During problem solving, when impulsive children discover effective strategies, they seldom employ such strategies consistently.

Morgan also investigated whether impulsive children were global or detailed problem-solvers. He identified that impulsive children process perceptual information in a global manner whilst reflective individuals are more analytical. Zelinker and Jeffrey (1976) also reported that reflective individuals tend to analyse stimuli into component features, whereas impulsives treat the stimulus as a whole. According to the authors, reflectives would excel on tasks requiring attention to detail, whereas impulsives would perform better on tasks amenable to a global approach such as template matching. Zelinker and Jeffrey identified that impulsives performed better than reflectives when a change to be detected in a visual discrimination task was located in the contour (global analysis) rather than within the image (detailed analysis).

\subsection{Academic Performance}

Gregory (1989) examined a number of studies and reported that reflectives performed better than impulsives on tasks such as matching to samples (Kogan 1976), inductive reasoning (Ault 1973; Kagan, Pearson \& Welch 1966), serial learning (Kagan 1966; Kagan et al, 1964), recognition memory (Siegel, Kirasic and Kilberg,1973) and reading (Erickson, Stahl and Rinehart 1985; Halpern 1984; Kagan 1965). Furthermore, Cathcart and Liedtke (1969) recognised the superior performance of reflectives on arithmetic achievement whilst Klein, Blockovich, Buchalter and Huyghe (1976) found that reflectives made fewer errors than impulsives on a convergent problem-solving task.

Fink and McCown (1993) explained that impulsivity seems to be inversely related to academic achievement. Impulsivity seems to be a moderator variable between intelligence and academic success. For example, individuals who are high in impulsivity and have high academic ability tend to have lower grades than individuals with high academic ability and low impulsivity (Helmers, Young \& Pihl 1995; Zeidner 1995). An explanation is that individuals with a poor academic performance tend to show an impulsive/careless problem-solving style. They use poorer problem-solving strategies in tasks where the response is not as obvious and gives the first answer that comes to mind (Fink \& McCown 1993).

In a similar vein, McMurran, Blair and Egan (2002) proposed that impulsivity may be an obstacle to learning in the early development years. For example, Sternberg and Zhang (2001) discussed that impulsive children make relatively more errors while reading prose, on serial recall tasks and visual discrimination.

However, these studies do not discuss differences between boys and girls of school age. Of relevance, Gurian and Stevens (2004) as well as Sax (2005) elucidated that girls are better at object discrimination, can deal with moderate stress such as timed tests less successfully, have more serotonin and oxytocin and so make fewer impulsive decisions compared with boys. That is, girls tend to think more of the consequences of their actions.

This paper investigates the nature of interest and its bearing on simple problem-solving matching tasks. The capacity to reflect may depend on how interested people are in things and this is symptomatic of either a hobby or past-time, or stimulation derived from the environment. One instrument used to find out how reflective or impulsive children are is the 'matching familiar figures test' and the methodology reported in this paper draws on research by conducted by Kagan (1966). Research took place at primary schools located in a borough of London in the U.K. Schools offer support for special educational needs. Bilingual staff help with pastoral care and child-centred activities, such as arts and crafts, computer programmes/games and quiet areas for reading. 


\section{Methods and Materials}

Twelve volunteers from year 3 classes; 6 girls and 6 boys from 5 primary schools were interviewed individually and asked what they found interesting and not interesting. For the purposes of completion of this interview, it was explained to participants that a hobby is a favourite pursuit and an interest is what they like; a curiosity, something that is given attention to and that triggers excitement.

Approximately two weeks later, pupils were administered a practice test to help them become familiar with the procedure. This test involved making matches to things which participants were familiar with, that is a 'face (Figure 1), chair, bus and a house.

\section{$A$}
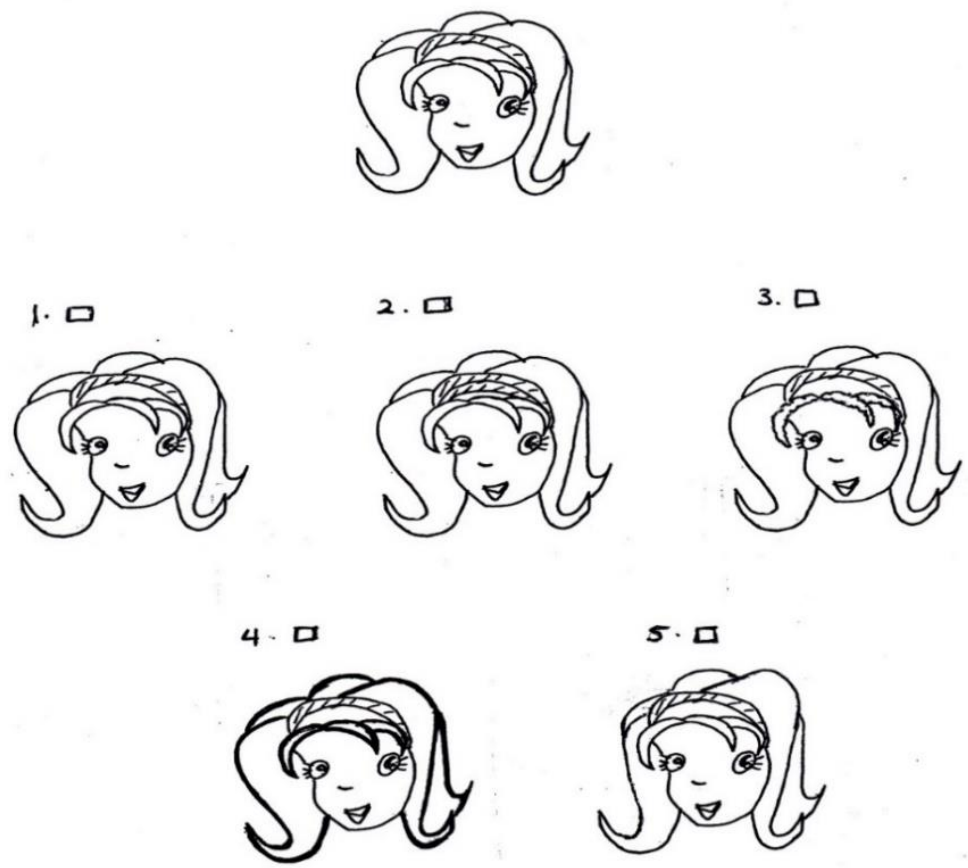

Figure 1 . The first matching activity of the practice test (a face)

The test drawings had variations based on size of things on the main forms of the pictures, number of things on pictures, distances between things and where they are placed, that is at opposite ends on drawings and thickness of lines.

\subsection{Practice Test}

Pupils were instructed as follows:

"You will be presented first with a practice test and you are required to match 1 of 5 pictures to a picture labelled $\mathrm{A}$ at the top of the page. There are boxes above each picture. Put a tick in one of the boxes when you have decided which picture matches picture A at the top of the page".

"I will count 1, 2, 3 (seconds). Put up your hand when you have made a match and write the number I say on the page. Any questions? Let's begin. Now read the first page of the test material (pause). This is a short introduction to the test booklet". I continued "turn over the page and complete the first match".

I began to count $1,2,3,4$, etc. and pointed to students as they put up their hands. This instructed pupils to write a number in seconds on the page where the match was made. After everyone had recorded a number, students were instructed to turn over the page. I continued "please put a tick in one of the boxes which shows how interested you are in the pictures. Very interested means that the pictures are interesting and disinterested means that you do not like the pictures. Do you have any questions? Okay now put a tick in one of the boxes." 
I continued. "The correct answer is number one for the first match you made, that is the 'face'. Who has the correct answer?" For those students who had the wrong answer, I explained individually why the answer was incorrect. I continued, "you have six minutes to finish the rest of the test. Please turn over the page. Remember, that when you have made a match put your hand up and write a number on the page. We will turn to the interest sheet together when everyone has made a match to the pictures. You will begin now." I started to count 1, 2, 3, etc.

\subsection{Main Test}

Immediately after this practice test, participants completed the main test consisting of 12 items. There were 3 themes participants found interesting and 3 they were not interested in. Each theme consisted of 2 items. After matches were made participants stated their interest/disinterest using tick boxes (as with the practice test). This was along a dimension of very interested $(\mathrm{Vi})$, slightly interested $(\mathrm{Si})$, neither interested or disinterested (Ni/Di), slightly disinterested (Sd) and very disinterested (Vd).

For participant 1 of a school for each gender, the presentation was AAA then $\mathrm{BBB}$ then $\mathrm{AB}$ $\mathrm{AB} \mathrm{AB}, \mathrm{BBB}$ AAA, BA BA BA, BAA BBA, ABB AAB. A were things pupils found interesting and $\mathrm{B}$ were things they were not interested in. This ensured that participants were not presented with similar/the same tests. Participants were instructed:

"This test is like the one you have just seen, but this time there are twelve matches to be made. I will count 1,2,3 and so on. When you have made a match, put up your hand and write the number which I have just counted on the page. Then after each of two matches, put a tick on the sheet stating your interests (any questions?)". I'd say you've got three minutes to complete the test. If you have missed a number, put both hands up and I'll see you'.

On completion of this test, all pupils were asked to complete an interview asking about the strategies (see appendix) they used when making matches as well as how they complete work and other activities at school.

\section{Results}

\subsection{Interest Types}

Participants tended to change how interested they were in items from when they were initially interviewed and when they completed tests, and this resulted in a larger number of things participants found interesting. Girls were interested in for example, reading, dancing, singing, boy bands, dolls, computers, Harry Potter books tennis etc, and boys were interested in cars, planes, Pokémon (video games), football, cricket, wrestling, television and computers. On observation across 5 schools, groups of year 3 in each school shared similar interests.

Results of girls and boys' errors on completing matching tasks with interest levels are presented in bar charts. Figure. 2 shows that boys over all matches produced more errors than girls.

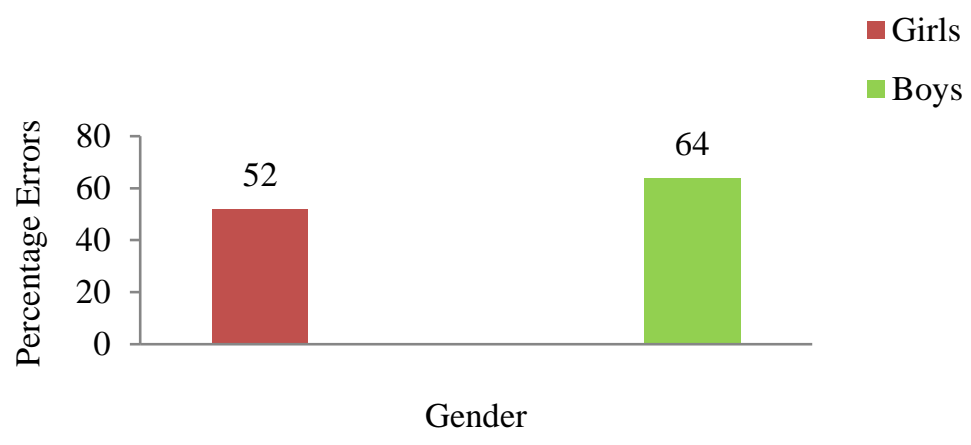

Figure 2. Bar chart showing percentage errors for males and females 


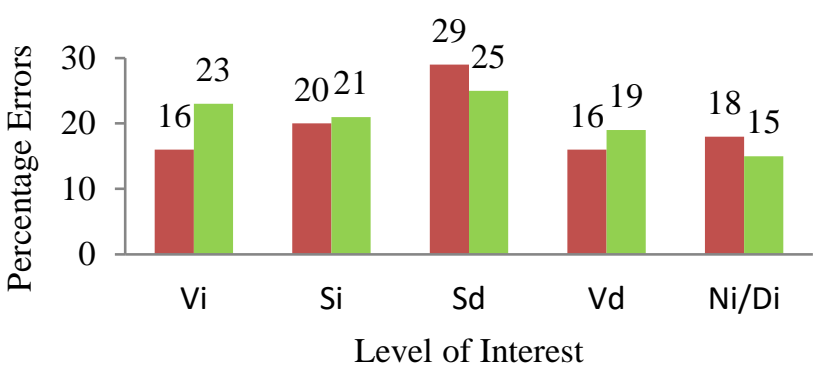

- Girls

Boys

Figure 3. Bar chart showing percentage errors for each level of interest between gender

Girls produced fewer errors than boys with those themes they found very interesting or generally interesting but displayed an approximately equal number of errors with themes they were not interested in. With themes pupils were neither interested nor disinterested in, boys made fewer errors.

\subsection{Time}

Across all matching tasks, girls performed slower than boys. That is, girls were slower (average of $11.9 \mathrm{~s}$ ) than boys with themes they found interesting. Girls were also slower than boys in making matches with themes they were neither interested/disinterested in, slightly disinterested as well as very disinterested in.

Table 1.

Mean times for levels of interest $(s)$

\begin{tabular}{lcccccc}
\hline & $\begin{array}{c}\text { Very } \\
\text { Interested } \\
(\mathrm{Vi})\end{array}$ & $\begin{array}{c}\text { Slightly } \\
\text { Interested } \\
(\mathrm{SI})\end{array}$ & $\begin{array}{c}\text { Neither } \\
\text { Interested/Disinterested } \\
(\mathrm{Ni} / \mathrm{Di})\end{array}$ & $\begin{array}{c}\text { Slightly } \\
\text { Disinterested } \\
(\mathrm{SD})\end{array}$ & $\begin{array}{c}\text { Very } \\
\text { Disinterested } \\
(\mathrm{VD})\end{array}$ & $\begin{array}{c}\text { Total } \\
\text { Mean } \\
\text { Time }\end{array}$ \\
\hline Girls & 12.43 & 11.44 & 10.21 & 10.63 & 11.50 & 56.21 \\
Boys & 8.49 & 8.56 & 9.63 & 7.75 & 7.53 & 41.96 \\
Total Mean & 20.92 & 20.00 & 19.84 & 18.38 & 19.03 & \\
Time & & & & & \\
\hline
\end{tabular}

The following graph illustrates the combined data of girls' and boys' interests, disinterests as well as those things which girls and boys were neither interested nor disinterested in. The graph shows that boys were quicker with all tasks.

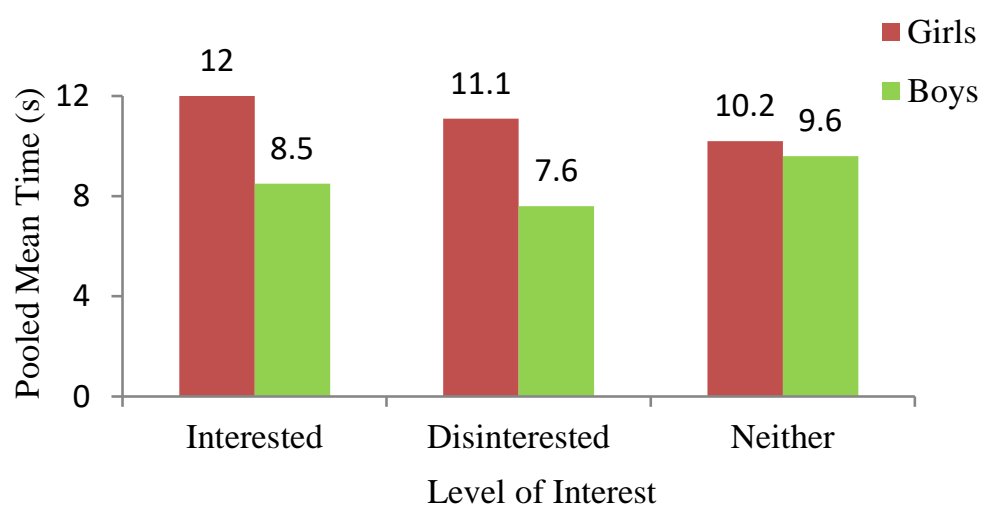

Figure 4. Bar chart showing pooled mean times (seconds) of interest and disinterest in items for boys and girls 
Across the dimension of very interested to very disinterested, t-tests showed significant differences in time taken to complete matches for those themes pupils found very interesting, were slightly disinterested in and those they were neither interested/disinterested in.

Table 2.

T-tests comparing mean times for girls and boys

\begin{tabular}{|c|c|c|c|c|c|}
\hline & $\begin{array}{l}\text { Number of boys (B) } \\
\text { and girls }(\mathrm{G})\end{array}$ & $\begin{array}{c}\text { Type of } \\
\text { hypothesis/degrees of } \\
\text { freedom (df) }\end{array}$ & t-test & $\mathrm{t}$-crit & significance \\
\hline VI & $\begin{array}{l}\mathrm{G}=81 \\
\mathrm{~B}=101\end{array}$ & $\begin{array}{l}\text { 2-tailed } \\
\mathrm{df}=90\end{array}$ & 0.36 & 1.664 & $\mathrm{p} \leq 0.05^{*}$ \\
\hline SI & $\begin{array}{l}\mathrm{G}=20 \\
\mathrm{~B}=23\end{array}$ & $\begin{array}{c}\text { 2-tailed } \\
\mathrm{df}=21\end{array}$ & 1.39 & 1.678 & $\mathrm{p} \geq 0.05$ \\
\hline NI/DI & $\begin{array}{c}\mathrm{G}=12 \\
\mathrm{~B}=8\end{array}$ & $\begin{array}{c}\text { 2-tailed } \\
\mathrm{df}=9\end{array}$ & 2.15 & 1.734 & $\mathrm{p} \leq 0.05^{*}$ \\
\hline SD & $\begin{array}{l}\mathrm{G}=4 \\
\mathrm{~B}=6\end{array}$ & $\begin{array}{c}\text { 2-tailed } \\
\mathrm{df}=4\end{array}$ & 4.86 & 1.860 & $\mathrm{p} \leq 0.05^{*}$ \\
\hline VD & $\begin{array}{l}\mathrm{G}=48 \\
\mathrm{~B}=47\end{array}$ & $\begin{array}{l}\text { 2-tailed } \\
\mathrm{df}=47\end{array}$ & 0.99 & 1.678 & $\mathrm{p} \geq 0.05$ \\
\hline
\end{tabular}

\subsection{Strategies}

Boys used random examination more than girls while girls tended to use ordered strategies. The following were strategies participants used:

A. Participants looked at picture A and then look at the others and make comparisons randomly, or not in any ordered way.

B. Decided if picture A is the same as picture 1, then picture 2, then 3, 4, 5, in an ordered way. C. Participants looked at everything at once and then decided which one looked different to picture A.

D. Participants looked at picture 1, then compared it to picture A, then picture 2 and compared it, and so on in an ordered way.

E. Participants looked at one of the lower pictures first, then compared it to picture A, then looked at another picture and so on randomly or in any order.

Girls used more of strategy B and less of C. Boys on the other hand used more of strategy A and less of strategy D.

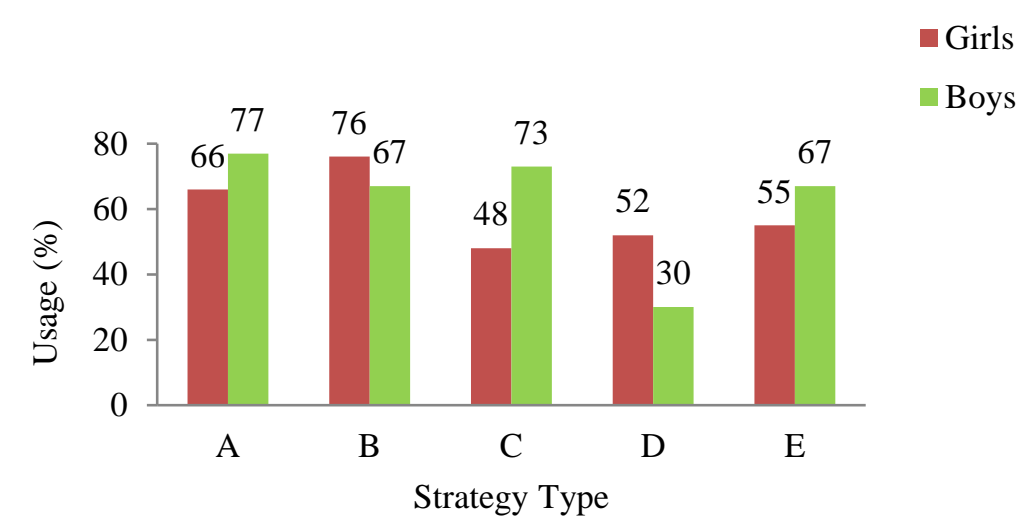

Figure 5. Bar chart showing percentage use of strategy type for girls and boys 


\section{Discussion}

\subsection{Change of Interest}

Pupils tended to change how interested they were in items from when they were initially interviewed and when they completed tests. Pupils of the 7-8 year age range are possibly more changeable within a relatively short time period in what they find interesting and so it would be worthwhile to carry out further research with a older age range, perhaps 9-11 year olds in order to compare stages at which interests are more stable.

\subsection{Time, Strategies and Errors}

All participants completed the tests within the time limit of 3 minutes.

Ordered examination by girls produced fewer errors than boys and overall girls spent longer making matches. This was especially evident with themes girls found interesting. Boys' use of random examination strategies was counterproductive to making successful matches.

Approximately equal number of errors were produced by boys and girls with items they found least interesting. In this case, girls would have tended to use more random strategies when completing matches with things they find least interesting in comparison with things they find interesting.

By using ordered examination, girls were inclined to make careful examination of the pictures and this supports Messer's (1976) findings that reflexives gather information carefully to make decisions. Quicker participants used fewer effective strategies, and this supports Morgan's (1997) conclusions.

It was also clear that boys are more likely to use global problem-solving strategies, that is are more impulsive than girls who are likely to analyse component features of the pictures. These findings confirm those of Morgan (1997) and Zelinker and Jeffery (1976, 1979). Gagné (1985, p.33) asserted that strategies will lead learners to arrive at answers but can be influenced by teaching styles.

\subsection{Teacher and participants' comments}

Teacher comments generally were that girl participants "complete all subjects slowly and less carefully". Girls felt that they can be impulsive at times but worry if they make mistakes. They tend to spend more time with things they like. For boys, teachers commented that they "complete tasks quickly and less carefully in many subject areas". Boys commented that they like to spend less time with things they do not like and do not worry if they make mistakes. The results tend to support Kagan et al's (1963) findings that reflective individuals make fewer errors; in this case this is mainly true for items/things which participants found interesting.

\subsection{Implications}

It is apparent that both boys and girls tend to spend more time with things they find interesting compared with those which are uninteresting, or they are neither interested nor disinterested in. That is, pupils are more reflective with things of interest. It also evident that the age range of 7-8 are changeable in what they find interesting as hobbies and interests are not yet well developed or are beginning to form.

The type of strategies participants used with making successful matches were ordered and this was mostly among girls. Teachers could train boys to problem-solve for example using those strategies which girls use. As pupils are changeable from what they like or prefer to do it is recommended that teachers should be more concerned with how pupils examine and analyse tasks and problems regardless of perceived impulsivity/reflectivity of pupils.

Specialist subject teachers could be made available at schools to develop pupils' interests and strengths. Grasha (1996) proposed that the avoidant style may be present among pupils. They are uninterested in learning and often absent while those with participant styles tend to be 
interested in activities in class and will meet teachers' expectations. The way boys and girls react to different learning conditions could be explored using Grasha's model and findings. According to Riding (2002), pupils should be encouraged to choose learning materials they prefer and be aware of the strengths and weaknesses of their style. Teachers will encourage pupils to choose appropriate styles. Additionally, teachers will also recognise that hindrances to learning could be due to poor information processing by pupils which may be because of their cognitive style(s) or loss of information during learning due to pupils' slow cognitive processing. Teachers will therefore present learning materials and use teaching styles which help pupils reach goals. The influence of impulsivity-reflectivity of pupils could be explored in this context.

\section{References}

Abrantes, J.L., Lages, L.F. \& Seabra, C. (2007). Pedagogical affect, student interest and learning performance. Journal of Business Research, 60, 960-964. https://doi.org/10.1016/ j.jbusres.2006.10.026

Ault, R.L. (1973). Problem-solving strategies of reflective, impulsive, fast-accurate and slowinaccurate children. Child Development, 47,227-231. https://doi.org/10.2307/1128045

Bandura, A. (1977). Self-efficacy: The exercise of control. Freeman: New York.

Cathcart, W.G. \& Liedtke,W. (1969). Reflectives/Impulsives and mathematics achievement. The Arithmetic Teacher, 16, 565-567.

Cavilla, D. (2017). The effect of student reflections on academic performance and motivation. Special collection innovative teaching and differential instruction to cater for student diversity, Education, 7 (3), 1-13.

Csikszentmihalyi, M. (1990). Flow: The psychology of optimal experience: Harper and Row: New York.

Csikszentmihalyi, M., \& Nakamura, J. (1989). The dynamics of intrinsic motivation: A study of adolescents. In R. Ames \& C. Ames (Eds.). Research on Motivation in Education (Vol. 3, pp. 45-71). San Diego, CA: Academic Press.

Deci, E.L. (1992). The relation of interest to the motivation of behaviour: a self-determination theory perspective. In K.A. Renninger, S. Hidi and A. Krapp (Eds.), The role of interest in learning and development (pp. 43-70). Lawrence Erlbaum Associates: Hillsdale, NJ. https://doi.org/10.1002/acp.2350080510

Erickson, L.G., Stahl, S.A. \& Rinehart, S.D. (1985). Metacognitive abilities of above and below average readers. Effects of conceptual tempo, passage level and error type on error detection. Journal of Reading Behaviour, 17 (3), 235-252. https://doi.org/10.1080/ $\underline{10862968509547542}$

Eska, B. \& Black, K.N. (1971). Conceptual temp in young grade -school children. Child Development, 45, 505-516. https://doi.org/10.2307/1127483

Fink, A. D. \& Mc Cown, W.G. (1993). Impulsivity in children and adolescents: Measurement, causes and treatment. In W. Mc. Cown, M. Shure and J. Johnson (Eds.). The impulsive client, theory, research and treatment (pp. 279-308). American Psychological Association: Washington D.C. https://doi.org/10.1037/10500-015

Gagné, E. D. (1985, p.33). The cognitive psychology of school learning. Little, Brown and Company: Boston, MA. 
Grasha, A. F. (1996). Teaching with Style: A Practical Guide to Enhancing Learning by Understanding Teaching and Learning Styles. Alliance Publishers: Pittsburgh, PA.

Gregory, D.C. (1989). Reflection-Impulsivity and the performance of fifth grade children on two art tasks. Studies in Art Education. A Journal of Issues and Research, 31 (1), 27-36. https://doi.org/10.2307/1320887

Gurian, M. \& Stevens, K. (2004). With boys and girls in mind. Educational leadership, 62 (3), 21-26.

Halpern, H.G. (1984). An investigation of reading and conceptual tempo measures. Reading word, 24, 90-96. https://doi.org/10.1080/19388078409557807

Harackiewicz, J., Smith, J.L. \& Priniski, S.J (2016). Interest matters: The importance of promoting interest in education. Policy Insights from the Behavioural and Brain science, 3 (2). 1-8. https://doi.org/10.1177/2372732216655542

Helmers, K.F, Young, S.N. \& Pihl, R.O. (1995). Assessment of measures of impulsivity in healthy male volunteers. Personality and Individual Differences, 6, 927-935. https://doi.org/10.1016/s0191-8869(95)00107-7

Kagan, J. (1965). Refection-Impulsivity and reading ability in primary grade children. Child Development, 36, 609-628. https://doi.org/10.2307/1126908

Kagan, J. (1966). Reflection-impulsivity: The generality and dynamics of conceptual tempo. Journal of Abnormal Psychology, 71, 17-27. https://doi.org/10.1037/h0022886

Kagan, J. (1971). Infant Precursors. In Kogan, N. (1976) Cognitive Styles in Infancy and Early Childhood. Lawrence Erlbaum Associates: Hillsdale, New Jersey.

Kagan, J., Moss, H.A. \& Sigel, I.E. (1963). Psychological significance of styles of conceptualisation. Monographs of the Society for Research in Child Development. https://doi.org/10.2307/1165673

Kagan, J., Pearson, J.\& Welch, L. (1966). Modifiability of an impulsive tempo. Journal of Educational Psychology, 57, 357-65. https://doi.org/10.1037/h0023960

Kagan, J., Rosman, B.L., Day, D., Albert, J. \& Phillips, W. (1964). Information processing in the child: significance of analytic and reflective attitudes. Psychological Monographs: General and Applied, 78, whole no. (578). https://doi.org/10.1037/h0093830

Klein, G. A, Blockovich, R. N., Buchalter, Pepsi S. \& Huyghe, L. (1976). Relationship between reflectivity impulsivity and problem-solving. Perceptual and Motor Skills, 42, 67-73. https://doi.org/10.2466/pms.1976.42.1.67

Kogan, N. (1976). Cognitive styles in infancy and early childhood. Wiley: New York.

Köller, O., Baumert, J. \& Schnabel, K. (2001). Does interest matter? The relationship between academic interest and achievement in mathematics. Journal of Research in Mathematics Education, 32(5), 448-470. https://doi.org/10.2307/749801

Loewenstein, G. (1994). The psychology of curiosity: A review and reinterpretation. Psychological Bulletin, 116, 75-98. https://doi.org/10.1037/0033-2909.116.1.75

McMurran, M., Blair, M. \& Egan, V. (2002). An investigation of the correlation between aggression, impulsiveness, social problem-solving and alcohol use. Aggressive Behaviour, 28, 439-445. https://doi.org/10.1002/ab.80017

Messer, S.B. (1976). Reflection-Impulsivity: A review. Psychological Bulletin, 83, 1026-1052. https://doi.org/10.1037/0033-2909.83.6.1026 
Morgan, H. (1997). Cognitive Styles and Classroom Learning. Praeger Publishers: Westport, CT.

Riding, R. (2002). School Learning and Cognitive Style. David Fulton Publishers: London.

Sax, L. (2005). Why Gender Matters. Broadway books: New York.

Siegel, A.W., Kirasic, K.C. \& Kilburg, R.R. (1973). Recognition memory in reflective and impulsive preschool children. Journal of Child Development, 44 (3), 651-656. https://doi.org/10.2307/1128025

Snow, R.E. (1992). Aptitude theory: Yesterday, today and tomorrow. Educational Psychologist, 27, 5-32. https://doi.org/10.1207/s15326985ep2701_3

Spinella, M., \& Miley, W. M. (2003). Impulsivity and academic achievement in college students. College Student Journal, 37(4), 545-549.

Sternberg, R.J.\& Zhang, Li-Fang. (2001). Perspectives on Thinking. Learning and Cognitive Styles. Lawrence Erlbaum Associates: London.

Zeidner, M. (1995). Personality trait correlates of intelligence. In D.H. Saklofske and M. [39] Zeidner (Eds.), International Handbook of Personality and Intelligence (1995) (pp. 299320). Plenum Press: New York. https://doi.org/10.1007/978-1-4757-5571-8_15

Zelinker, L., \& Jeffrey, S. (1976). Inter-language. International review of applied linguistics, $10(2), 201-223$. 


\section{Appendix}

\section{INTERVIEW}

1. How did you make these matches? Did you:

(a) Look at picture A and then look at the others and make comparisons randomly?

$$
\text { Yes No }
$$

(b) Decide if picture $\mathrm{A}$ is the same as picture 1, then picture 2, then 3, 4, 5, by ordered examination.

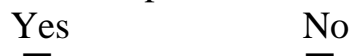

(c) Look at everything at once and then decide which one looks different to picture A?

Yes No

(d) Examine picture 1 and then picture A?

Yes No

(e) Examine picture 2 and then picture A?

Yes No

(f) Examine picture 3 and then picture A?

Yes No

(g) Examine picture 4 and then picture A?

Yes $\quad$ No

(h) Examine picture 5 and then picture A?

Yes No

(i) Look at the simplest picture to yourself and then decide if it's the same as picture A?

$$
\text { Yes No }
$$

(j) Examine any picture and then picture A?<smiles>[Mg][Mg]</smiles>

(k) Look at the most complex picture, and then decide if it's the same as picture A?

$$
\text { Yes No }
$$

2. Tell me about your-self. How do you complete schoolwork and other activities? 